\title{
Hepatitis B virus-associated hepatocellular carcinoma in South Africa in the era of HIV
}

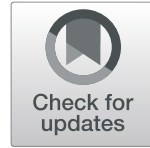

Tongai Gibson Maponga ${ }^{1 *}$ (D, Richard H. Glashoff ${ }^{2,3}$, Hannali Vermeulen ${ }^{4}$, Barbara Robertson ${ }^{5}$, Sean Burmeister ${ }^{6}$, Marc Bernon ${ }^{6}$, Jones Omoshoro-Jones ${ }^{7}$, Paul Ruff ${ }^{6}$, Alfred I. Neugut ${ }^{9,10,11}$, Judith S. Jacobson ${ }^{10,11}$, Wolfgang Preiser ${ }^{1,3}$ and Monique I. Andersson ${ }^{1,12}$

\begin{abstract}
Background: Patients co-infected with hepatitis B virus (HBV) and the human immunodeficiency virus (HIV) are at risk of developing hepatocellular carcinoma (HCC). In sub-Saharan Africa, the overlap between high HIV and HBV prevalence may increase the incidence of HCC. This study investigated the impact of HBV/HIV co-infection on age at presentation and survival of HCC.

Methods: Ethical approval was obtained to recruit, following informed written consent, patients diagnosed with HCC at oncology units at four South African hospitals. Between December 2012 and August 2015, patients newly diagnosed with HCC were recruited and provided demographic and clinical data and blood specimens. Patients were tested for HBV, hepatitis C virus (HCV) and HIV. Survival data was available for a subset of patients.

Results: Of 107 HCC cases, 83 (78\%) were male. Median age was 46 years (range 18 to 90 years), 68/106 (64\%) were HBsAg-positive, and 22/100 (22\%) were HIV infected. Among HBV surface antigen (HBsAg)-positive HCC cases, 18/66 (27\%) were HIV-infected compared to 3/34 (9\%) among those that were HBsAg-negative $(p=0.04)$. A greater proportion of HBV/HIV co-infected cases were female than HBV mono-infected (6/18,33\% vs 6/47, 13\%; $p=0.005)$. In addition, HBV/HIV co-infected females presented at a younger mean age (36.8 years) than HBV mono-infected women (50.5 years) $(p=0.09$ ). Median survival was 82 days among the HIV-infected HCC patients compared to 181 days among those without HIV $(p=0.15)$.

Conclusions: HCC is an important complication in the HIV/HBV infected patient. HIV-positive patients presented with HCC at a younger age than HIV-negative patients, this effect appears to be greater in women. These data provide more evidence supporting the call to address. HCC as a cause of morbidity and mortality in the HBV/HIV co-infected patient population. (281 words).
\end{abstract}

Keywords: Hepatitis B infection, HIV infection, Hepatocellular carcinoma, Natural history, Age at presentation, Survival

\footnotetext{
*Correspondence: tongai@sun.ac.za

${ }^{1}$ Division of Medical Virology, Stellenbosch University, Faculty of Medicine and Health Sciences, Cape Town, South Africa

Full list of author information is available at the end of the article
}

(c) The Author(s). 2020 Open Access This article is licensed under a Creative Commons Attribution 4.0 International License, which permits use, sharing, adaptation, distribution and reproduction in any medium or format, as long as you give appropriate credit to the original author(s) and the source, provide a link to the Creative Commons licence, and indicate if changes were made. The images or other third party material in this article are included in the article's Creative Commons licence, unless indicated otherwise in a credit line to the material. If material is not included in the article's Creative Commons licence and your intended use is not permitted by statutory regulation or exceeds the permitted use, you will need to obtain permission directly from the copyright holder. To view a copy of this licence, visit http://creativecommons.org/licenses/by/4.0/ The Creative Commons Public Domain Dedication waiver (http://creativecommons.org/publicdomain/zero/1.0/) applies to the data made available in this article, unless otherwise stated in a credit line to the data. 


\section{Background}

Hepatocellular carcinoma (HCC) is the second most common cause of cancer mortality worldwide [1]. SubSaharan Africa (SSA) has the second highest number of HCC cases worldwide after South East Asia [2]. It is estimated that $60 \%$ of all HCC cases in developing countries are due to chronic HBV infection (CHB) [3]. This is despite the availability of a safe and effective vaccine for over three decades.

HCC in African populations appears to affect men more commonly than women [4]. Patients tend to present very late with malignancy and time to death post-diagnosis is short. The data from previous studies suggests that the average survival time from the onset of symptoms is around 11-12 weeks and 6-7 weeks from the time of diagnosis $[5,6]$, with less than $10 \%$ of patients surviving beyond a year after diagnosis [7].

$\mathrm{CHB}$ has an intermediate to high prevalence (5-7\%) among adults in southern SSA [8], although studies suggest the prevalence in South Africa is lower than this at around $2-3 \%[9,10]$. SSA has the highest number of people living with human immunodeficiency virus (HIV) infection [11]. HIV as a risk factor for the development of cancer was first recognized because of its strong association with other virally driven malignancies, such as Kaposi's sarcoma secondary to human herpes virus-8 (HHV8) infection, and non-Hodgkin's lymphoma with Epstein-Barr virus (EBV) infection. These cancers usually develop in patients with untreated HIV infection [12, 13] and are now declining because of combined antiretroviral therapy (ART) [14]. However, the improved longevity in treated HIV infection has increased the incidence of other serious non-AIDS-related malignancies, including HCC [15-17].

Little is known about the natural history of HCC in the $\mathrm{HBV} / \mathrm{HIV}$ co-infected patient. In fact, the question of whether HIV increases the risk of $\mathrm{HCC}$ in patients with $\mathrm{CHB}$ still remains largely unanswered. Two studies from resource rich settings suggest that HIV may hasten the evolution of HBV-related HCC, resulting in an earlier age of presentation in the HIV co-infected patient $[18,19]$. These data were confirmed in a small West African study of $60 \mathrm{HCC}$ patients in which seven HIVinfected cases presented at a younger median age of 32 years [interquartile range: 31-44] compared to 49 years [interquartile range; 44-59] among 53 patients without HIV infection [13]. A case-control study conducted within the Swiss HIV Cohort Study reported that decreased CD4+ cell counts were associated with an increased risk of HCC development among HIV-infected patients who were co-infected with HBV [20]. However, a recent case-control study in South Africa did not find an increased risk for $\mathrm{HCC}$ in $\mathrm{HIV}$-infected individuals [21]. Little is known about $\mathrm{HCC}$ in the $\mathrm{HIV} / \mathrm{HBV}$ infected African patient. The aim of this study was to describe the natural history of HCC in an HBV/HIV coinfected and monoinfected population.

\section{Methods and materials Study population}

Between December 2012 and August 2015, patients who were newly diagnosed with primary $\mathrm{HCC}$ were prospectively recruited into the study from oncology departments at four university teaching hospitals in South Africa: Tygerberg Hospital and Groote Schuur Hospital in the Western Cape Province and Chris Hani-Baragwanath Academic Hospital and Charlotte Maxeke Johannesburg Academic Hospital in Gauteng Province. The diagnosis of HCC was based on radiological examination by contrast-enhanced computed tomography, abdominal ultrasound scan and/or magnetic resonance imaging and clinical findings. An experienced oncologist reviewed all patients. A subset of 25 cases also had histologic diagnosis of HCC. Serum alpha-fetoprotein (AFP) was measured, but levels $<400 \mu \mathrm{g} / \mathrm{L}$ did not exclude diagnosis of HCC. Following consent patients were interviewed using a standardized questionnaire, had a physical examination and provided blood samples. Clinical laboratory data were extracted from clinical records. A sub-group of the patients recruited from the Western Cape, underwent follow up for survival analysis. This was achieved by means of following up cases via the South African Department of Home Affairs to determine date of death (where applicable) using the national identification number.

\section{Ethical considerations}

All participants were recruited following written informed consent according to the Declaration of Helsinki 2008. Ethical approval for the study was obtained from the health research ethics committees at Universities of Stellenbosch, Cape Town and Witwatersrand.

\section{Laboratory testing}

Blood specimens were collected in EDTA anticoagulant and SST tubes with silica clot activator upon enrolment into the study. The tubes were centrifuged to separate plasma or serum and stored at $-80{ }^{\circ} \mathrm{C}$ until they were used for serologic and molecular testing. The HBsAg test was performed using the DiaSorin Murex HBsAg Version 3 immunoassay kit (DiaSorin, Saluggia, Italy). $\mathrm{HBeAg}$ and antibodies to $\mathrm{HBeAg}$ (anti-HBe) were tested using the ETI-EBK PLUS and ETI-AB-EBK PLUS (DiaSorin), respectively. Total antibodies against $\mathrm{HBV}$ core antigen (anti-HBc) were measured using the Murex Anti-HBc (total) immunoassay kit (DiaSorin). Antibodies to $\mathrm{HCV}$ and HIV were tested on the Abbott Architect i2000SR immunoanalyzer (Abbott Laboratories, Abbott 
Park, Illinois, USA). HBV DNA quantification and genotyping were performed as previously described on HBsAg-positive samples [22, 23]. HBV genotypes were obtained using the online genotyping databases of Stanford University, the Max Planck Institute for Informatics and the National Library of Medicine HBV genotyping tool. HCV viral load was tested using the COBAS AmpliPrep/COBAS TaqMan HCV assay.

\section{Statistical testing}

All data entry and storage were performed in Epi-Info 7 (Centres for Disease Control, GA, USA) and statistical analysis was carried out in Statistica version 12 (StatSoft, Oklahoma, USA). Non-parametric data or small-sample data were described using medians and interquartile ranges and compared using the Mann-Whitney test where there were only two groups or the Kruskal-Wallis test in cases of three or more groups. Data with normal distribution were described using means and 95\% confidence intervals. Comparisons were performed using the unpaired t-test where data were normally distributed. Categorical data were described using proportions and analysed using the chi-square test or Fisher's exact test, depending on the number of observations. Survival after diagnosis of HCC was evaluated using the Kaplan-Meier method, and comparisons between patients infected and uninfected with HIV were performed with the log-rank test. Graphs were constructed using GraphPad Prism version 5 (GraphPad Software, CA, USA). All hypothesis testing was done at $95 \%$ confidence intervals and results were regarded as significant if $p<0.05$.

\section{Results}

Demographic and clinical characteristics

A total of 107 HCC patients were recruited between December 2012 and August 2015. The mean age was 46 years (95\% CI: $43-49)$, range $18-90$ years. The majority were male $78 \%(83 / 107)$ and $55 \%(59 / 107)$ were Black African. Twenty two percent (22/100) of cases were HIV infected, of whom $91 \%(20 / 22)$ had evidence of current or past HBV infection. There was insufficient specimen for HIV testing for seven cases. Table 1 shows the demographic and clinical characteristics of the 100 patients with known HIV status.

The median serum AFP was $6176 \mu \mathrm{g} / \mathrm{L}$ (interquartile range: $120-47,750)$. Of 98 cases, 69 (70\%) had serum AFP greater than $400 \mu \mathrm{g} / \mathrm{L}$. The majority of cases were diagnosed using imaging modalities in combination with clinical laboratory data. Contrast-enhanced computed tomography $(\mathrm{CT})$ scan was done in 77 of 107 . Liver histological examination was done on 31/100 of cases on whom information was provided (data was missing on seven cases).
Table 1 Demographic and clinical characteristics of HCC cases by known HIV status

\begin{tabular}{|c|c|c|c|}
\hline & HIV-infected, N (\%) & HIV-uninfected, N (\%) & $\boldsymbol{p}$-value \\
\hline & $22(22)$ & $78(78)$ & \\
\hline \multicolumn{4}{|c|}{ Age groups (in years) } \\
\hline $18-34$ & $5(23)$ & $23(29.5)$ & 0.003 \\
\hline $35-49$ & $14(64)$ & $18(23)$ & \\
\hline $50-59$ & $2(9)$ & $23(29.5)$ & \\
\hline $60-90$ & $1(5)$ & $14(18)$ & \\
\hline \multicolumn{4}{|l|}{ Gender } \\
\hline Male & $14(64)$ & $64(72)$ & 0.03 \\
\hline Female & $8(36)$ & $14(18)$ & \\
\hline \multicolumn{4}{|l|}{ Race } \\
\hline African & $20(91)$ & $32(43)$ & 0.0004 \\
\hline Caucasian & $0(0.0)$ & $6(8)$ & \\
\hline Mixed & $2(9)$ & $36(49)$ & \\
\hline Missing data ${ }^{a}$ & 0 & 4 & \\
\hline \multicolumn{4}{|l|}{ Place of birth } \\
\hline Urban & $14(70)$ & $44(60)$ & 0.4 \\
\hline Rural & $6(30)$ & $29(40)$ & \\
\hline Missing data ${ }^{a}$ & 2 & 5 & \\
\hline \multicolumn{4}{|c|}{ Alcohol dependence } \\
\hline Yes & $5(24)$ & $15(21)$ & 0.7 \\
\hline No & $16(76)$ & $57(79)$ & \\
\hline Missing data ${ }^{a}$ & 1 & 6 & \\
\hline \multicolumn{4}{|c|}{ Known cirrhosis } \\
\hline Yes & $5(25)$ & $15(22)$ & 0.8 \\
\hline No & $15(75)$ & $52(78)$ & \\
\hline Missing data ${ }^{a}$ & 2 & 11 & \\
\hline \multicolumn{4}{|l|}{ HBsAg status } \\
\hline Positive & $18(82)$ & $47(60)$ & 0.06 \\
\hline Negative & $4(18)$ & $31(40)$ & \\
\hline \multicolumn{4}{|c|}{ Anti-HBc status } \\
\hline Positive & $20(91)$ & $62(83)$ & 0.5 \\
\hline Negative & $2(9)$ & $13(17)$ & \\
\hline Missing data ${ }^{a}$ & 0 & 3 & \\
\hline \multicolumn{4}{|l|}{ Anti-HCV } \\
\hline Positive & $1(5)$ & $7(9)$ & 0.7 \\
\hline Negative & $20(95)$ & $68(91)$ & \\
\hline Missing data & 1 & 3 & \\
\hline
\end{tabular}

Missing data ${ }^{a}$ not included in the statistical analysis

\section{Prevalence of HBV serological markers}

Of 106 serum samples tested (one had insufficient volume for testing), 68 (64.1\%, 95\% CI: 59-77) were seropositive for $\mathrm{HBsAg}$, and 85/103 (82.5, 95\% CI: 76-90) were anti-HBc positive. The mean age of the HBV- 
infected cases was 44 years (95\% CI: 41-47) compared to 49 years (95\% CI: 43-54) among those HBV-uninfected, $p=0.16$. Among the $34 \mathrm{HBsAg}$ negative samples, 17 (50\%, 95\% CI: 32-65) were positive for anti-HBc, indicating HBV exposure. Male HBsAg positive patients were younger (mean age 43.8 years, 95\% CI: 40.1-47.5) than male HBsAg negative patients (mean age 50.4 years, 95\% CI: 44.2-56.9), $(p=0.07)$. However, the HBsAgpositive female patients were similar in age ( 45.2 years, 95\% CI: 35.8-54.6) to the HBsAg negative females (45.6 years, 95\% CI: 32.9-58.2).

Of the 68 HBsAg seropositive patients, 65 were tested for HBeAg. There was insufficient serum in three cases. The overall prevalence of HBeAg among the HBsAg positive cases was 20/65 (31\%). Five of 11 female patients $(45 \%, 95 \% \mathrm{CI}: 15-74)$ were $\mathrm{HBeAg}-$ positive, while only 15 of 54 male patients $(28 \%, 95 \%$ CI: 14-40) were HBeAg positive, $p=0.29$.

\section{Association of HBV/HIV co-infection with demographic and clinical characteristics at presentation of $\mathrm{HCC}$}

Table 2 shows the demographic and clinical characteristics of the 100 patients with known HIV status. Of the 22 HIV-infected patients, 14 were receiving cART. Nine were prescribed tenofovir, lamivudine and efavirenz; one was on lamivudine, stavudine and nevirapine; for the remaining four, no data was available. The median CD4+ T cell count at time of HCC diagnosis was 293 cells/ $\mu \mathrm{L}$ (IQR: 200-602).

The mean age of HIV-infected patients at HCC diagnosis was 39.7 years (95\% CI: $36.0-43.5$ ); that of uninfected patients was 46.4 years (95\% CI: 42.8-50.0), $p=$ 0.07 . The mean age of HIV-infected female patients was 35.8 years (95\% CI: $34.1-40.0), 13$ years younger than the mean age of HIV-uninfected females, 48.5 years $(95 \% \mathrm{CI}$ : 37.4-59.6), $p=0.08$. The mean age of HIV-infected male HCC cases was 42.0 years (95\% CI: 36.6-47.4), the mean age of HIV-uninfected males was 45.9 years $(95 \%$ CI: 42.2-49.8) $p=0.4$.

Eighteen of the HIV-infected (81.8\%) and 47 (60.3\%) of the uninfected patients had active HBV infection (HBsAg seropositive) $(p=0.06)$. The two patients who were HIV infected and had no evidence of HBV infection, both had histological confirmation of the diagnosis. One of the two HIV-infected patients had a history of alcoholic liver disease as a risk factor.

HBV genotypes were determined for 43 cases, nine of whom were $\mathrm{HBV} / \mathrm{HIV}$ co-infected. All nine of the co-infected patients and 25/34 (74\%) of the monoinfected patients had HBV genotype A. HCC cases infected with HBV genotype A had a median age of 36 years (IQR: $31-48$ ) compared to 53 years (IQR: $50-$ 58 ) in those infected with HBV genotype $\mathrm{D}, p=0.008$.

\section{Prevalence of HCV infection}

Antibodies to $\mathrm{HCV}$ were detected in 10 of 101 cases (9.9, 95\% CI: 4.1-15.7). There was insufficient sample for testing in six cases. The mean age of the anti-HCV positive subjects was 57.5 years (95\% CI: 45.8-69.2), while that of the anti-HCV negative cases was 12 years younger, 44.6 years (95\% CI: $41.8-48.0) p=0.01$. Of the ten anti-HCV seropositive $\mathrm{HCC}$ cases, 9 (90\%) were male. Among the ten anti-HCV positive cases, three were $\mathrm{HBV} / \mathrm{HCV}$ co-infected while one case had triple infection with $\mathrm{HCV}, \mathrm{HBV}$ and HIV. Of eight anti-HCV positive cases, 5 (63\%) had detectable HCV RNA with a median of $6.27 \log 10$ copies/ml (IQR: $5.67 \log 10-6.42$ log10). Samples from four HCV-infected HCC cases were successfully sequenced - two cases were infected with $\mathrm{HCV}$ genotype $5 \mathrm{a}$ while one case each had genotype $1 \mathrm{a}$ and the other genotype $1 \mathrm{~b}$.

\section{Survival of HCC patients}

Of the 22 HIV-infected HCC patients, 15 (68.2\%) died during follow up, while of the 78 patients without HIV, $44(56.4 \%)$ died during follow-up. The Kaplan-Meier survival curves of the two groups were not significantly different, $p=0.15$. The survival curves of the HCC cases with and without HIV infection are shown in Fig. 1. Median survival was 82 days among the HIV-infected patients and 181 days among those without HIV.

\section{Discussion}

Primary liver cancer accounts for 600,000 deaths each year [24]. HCC is the most common primary liver cancer, accounting for over $90 \%$ of all cases [25]. Vaccination has been shown to reduce the incidence of HBVrelated liver cancer. However, the hepatitis B vaccine was not introduced into South Africa's Expanded Programme on Immunisation until 1996. Prior to that time, childhood-acquired HBV infections were common in much of Africa. All the HCC patients recruited into this study were born before 1996.

The prevalence of HIV among HCC patients in this study was $22 \%$ (95\% CI: 14-30), higher than the prevalence of HIV in the South African adult population, estimated at $14.4 \%$ among females and $9.9 \%$ among males from the 2012 South African National HIV Prevalence, Incidence and Behaviour Survey Report [26]. Moreover, the prevalence was particularly high among females in this study; $36 \%$ of whom were HIV-infected. The majority of HIV/HBV co-infected women were African Blacks, evidence of the vulnerability of this group to HIV infection within sub-Saharan Africa [27, 28]. HIV/HBV coinfected females were about 10 years younger at HCC diagnosis than HBV mono-infected females, although the difference did not reach statistical significance. Our observations are consistent with those of a few African 
Table 2 Demographic and clinical characteristics according to known HIV and HBsAg status

\begin{tabular}{|c|c|c|c|c|c|}
\hline & $\mathrm{HIV}+\mathrm{HBV}+$ & HIV- HBV+ & HIV+ HBV- & HIV- HBV- & \\
\hline & $18(18 \%)$ & 47 (47\%) & $4(4 \%)$ & $31(31 \%)$ & p-value \\
\hline \multicolumn{6}{|l|}{ Age groups (in years) } \\
\hline $18-34$ & $4(22)$ & $15(32)$ & $1(25)$ & $8(26)$ & \\
\hline $35-49$ & $12(67)$ & $13(28)$ & $2(50)$ & $5(16)$ & \multirow[t]{3}{*}{0.04} \\
\hline $50-59$ & $1(5.5)$ & $11(23)$ & $1(25)$ & $12(39)$ & \\
\hline $60-90$ & $1(5.5)$ & $8(17)$ & $0(0)$ & $6(19)$ & \\
\hline \multicolumn{6}{|l|}{ Gender } \\
\hline Male & $12(67)$ & $41(87)$ & $2(50)$ & $23(74)$ & \multirow[t]{2}{*}{0.1} \\
\hline Female & $6(33)$ & $6(13)$ & $2(50)$ & $8(26)$ & \\
\hline \multicolumn{6}{|l|}{ Ethnicity } \\
\hline Black African & $16(89)$ & $23(50)$ & $4(100)$ & $9(32)$ & \multirow[t]{4}{*}{0.006} \\
\hline Caucasian & $0(0)$ & $3(7)$ & $0(0)$ & $3(11)$ & \\
\hline Mixed ancestry & $2(11)$ & $20(43)$ & $0(0)$ & $16(57)$ & \\
\hline Missing data & 0 & 1 & 0 & 3 & \\
\hline \multicolumn{6}{|l|}{ Alcohol dependence } \\
\hline Yes & $4(22)$ & $8(18)$ & $1(3)$ & $7(25)$ & \multirow[t]{3}{*}{0.9} \\
\hline No & $14(78)$ & $36(82)$ & $2(67)$ & $21(75)$ & \\
\hline Missing data & 0 & 3 & 1 & 0 & \\
\hline \multicolumn{6}{|l|}{ Known cirrhosis } \\
\hline Yes & $5(29)$ & $12(27)$ & $0(0)$ & $3(13)$ & \multirow[t]{3}{*}{0.4} \\
\hline No & $12(71)$ & $32(73)$ & $3(100)$ & $20(87)$ & \\
\hline Missing data & 1 & 3 & 1 & 5 & \\
\hline \multicolumn{6}{|l|}{ HBeAg positive } \\
\hline Yes & $10(59)$ & $9(20)$ & \multirow[t]{3}{*}{$\mathrm{n} / \mathrm{a}$} & $\mathrm{n} / \mathrm{a}$ & \multirow[t]{3}{*}{0.003} \\
\hline No & $7(41)$ & $37(80)$ & & & \\
\hline Missing data & 1 & 1 & & & \\
\hline \multicolumn{6}{|l|}{ HBV genotypes } \\
\hline A & $9(100)$ & $25(76)$ & \multirow[t]{3}{*}{$\mathrm{n} / \mathrm{a}$} & $\mathrm{n} / \mathrm{a}$ & \multirow[t]{3}{*}{0.00009} \\
\hline $\mathrm{D}$ & $0(0)$ & $7(21)$ & & & \\
\hline$E$ & $0(0)$ & $1(3)$ & & & \\
\hline \multicolumn{6}{|l|}{ AFP $>400 \mu \mathrm{g} / \mathrm{L}$} \\
\hline Yes & $11(61)$ & $35(80)$ & $3(75)$ & $14(54)$ & \multirow[t]{3}{*}{0.1} \\
\hline No & $7(39)$ & $9(20)$ & $1(25)$ & $12(46)$ & \\
\hline Missing data & 0 & 3 & 0 & 5 & \\
\hline \multicolumn{6}{|l|}{ Child-Pugh } \\
\hline A & $9(60)$ & $30(68)$ & $2(67)$ & $14(59)$ & \multirow[t]{4}{*}{1.0} \\
\hline B & $5(33)$ & $11(25)$ & $1(33)$ & $8(33)$ & \\
\hline C & $1(7)$ & $3(7)$ & $0(0)$ & $2(8)$ & \\
\hline Missing data & 3 & 3 & 1 & 7 & \\
\hline \multicolumn{6}{|l|}{ Nodules at diagnosis } \\
\hline Single lesion < $2 \mathrm{~cm}$ & $3(19)$ & $5(12)$ & $0(0)$ & $4(14)$ & \multirow{4}{*}{1.0} \\
\hline Single lesion $2-5 \mathrm{~cm}$ & $0(0)$ & $0(0)$ & $0(0)$ & $1(4)$ & \\
\hline Single lesion $>5 \mathrm{~cm}$ & $2(12)$ & $6(14)$ & $0(0)$ & $4(14)$ & \\
\hline Multiple lesions & $11(69)$ & $31(74)$ & $1(100)$ & $19(68)$ & \\
\hline
\end{tabular}


Table 2 Demographic and clinical characteristics according to known HIV and HBsAg status (Continued)

\begin{tabular}{llllll}
\hline & HIV+ HBV+ & HIV- HBV+ & HIV+ HBV- & HIV- HBV- \\
& $18(18 \%)$ & $47(47 \%)$ & $4(4 \%)$ & $31(31 \%)$ & 3 \\
\hline Missing data & 2 & 5 & 1 & p-value \\
\hline
\end{tabular}

Missing/unknown data, (including cases with unknown HIV status) are excluded from the table and statistical analysis

studies that have evaluated the effect of HIV on the epidemiology of HCC in Africa [13]. These studies have reported that HIV-infected liver cancer patients were 10 years younger at diagnosis than patients without HIV.

The patients with HBV infection were younger at $\mathrm{HCC}$ diagnosis than those that were infected with $\mathrm{HCV}$ in this study. This finding is consistent with reports that $\mathrm{HCV}$-associated HCC tends to peak in the sixth decade of life and HBV-associated HCC in the fourth decade [29]. The differences in age at presentation probably reflect the ages of acquisition of viral hepatitis infection and the differing oncogenic processes of these two viruses. In sub-Saharan Africa, HBV infection is predominantly acquired early in childhood through vertical and horizontal transmission, while $\mathrm{HCV}$ is acquired, predominantly in high-risk groups, in adulthood. HCV associated HCC is more often associated with cirrhosis than HBV associated HCC, and therefore presenting later in life either in the context of liver cirrhosis.

We found that patients who were infected with HBV genotype A presented at a significantly younger age than those with genotype D. That finding is consistent with that of Kew et al., who described a mean age difference of almost 7 years [30]. The frequent absence of HBeAg and the basal core promotor mutations in genotype $\mathrm{D}$ compared to genotype A may provide an explanation for the difference in age at presentation between the two genotypes. $\mathrm{HBeAg}$ positivity, which normally denotes high HBV replication, is a known risk factor for HCC development and tends to be more prevalent, together with the basal core promoter mutations, in patients infected with genotype A compared to those with D [31].

Fifty-five percent of HCC patients in this study were Black Africans who are thought to be at higher risk of HCC than other racial groups due to greater exposure to factors predisposing to $\mathrm{HCC}$, such as dietary iron overload and HBV and HIV infection [32, 33]. Cirrhosis prevalence in $\mathrm{HBV}$-associated $\mathrm{HCC}$ among African patients has previously been reported to be $44-63 \%$ [34-36]. However, only $23 \%$ of our patients had known underlying cirrhosis at HCC diagnosis, probably because their diagnoses of cirrhosis were based on clinical rather than histological parameters. Clinical assessment of cirrhosis is known to result in under-diagnosis and under-reporting of its true prevalence, especially among patients with compensated cirrhosis. Studies from the United States have also found that cirrhosis was not identified

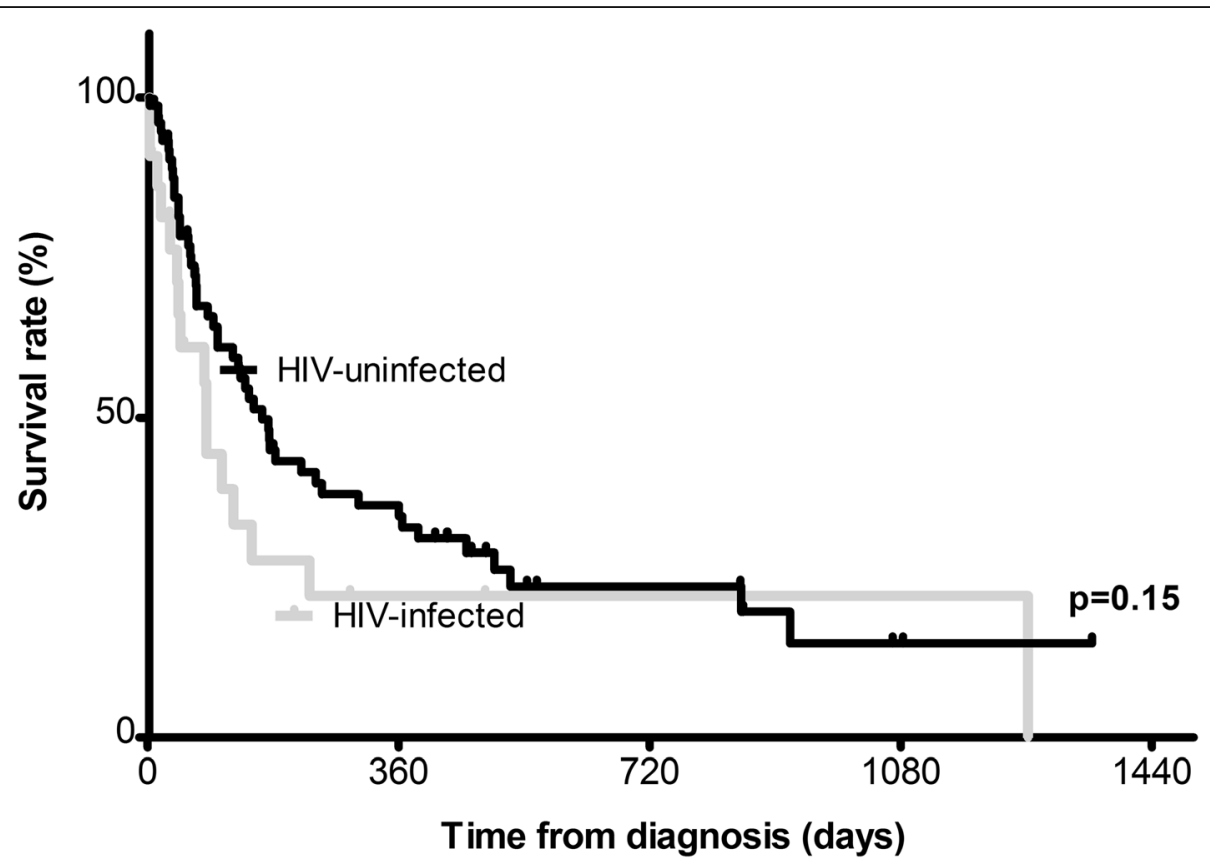

Fig. 1 Survival rates according to known HIV status. Comparison between Kaplan-Meier survival curves in 22 HIV-infected patients with HCC and 78 HIV-uninfected HCC patients. Patients whose HIV status was unknown were not included in this survival analysis 
among $24-30 \%$ of HCC patients who had underlying cirrhosis [37, 38]. In patients with hepatitis C, HCC invariably develops following cirrhosis such that early diagnosis of malignancy is diminished when cirrhosis is diagnosed late [38]. However, cirrhosis is not necessary for the development of HCC in CHB.

Our findings raise questions regarding implementation of current hepatitis B treatment and HCC screening guidelines in South Africa. Patients with viral hepatitis have access to tertiary level treatment and surveillance programmes but without wider access to screening for HBV infection, it is not possible to implement them. Unfortunately, many HBV infections are only diagnosed once they present with HCC. Few of our HBV-monoinfected patients had been screened and treated for $\mathrm{CHB}$ before their HCC diagnosis. As a result, many patients have radiological findings of multiple or large liver lesions at presentation. Only $30 \%$ of cases in this current study had histologic diagnosis of HCC. This has implications with regard to understanding the true burden of HCC with South Africa whose national cancer registry is pathology-based. As a result, there is an underestimation of the burden of HCC and this impacts on the allocation of resources towards the health burden.

Among these HCC patients in this study, survival was dismal regardless of HBV or HIV status. Although the HIV-infected HCC patients had a median survival of 82 days, compared to 181 days among those without HIV infection, the difference was not statistically significant. Nonetheless, the poor survival of HIV-infected patients compared to HIV-uninfected patients argues against the probability that the difference in age at diagnosis between HIV-infected and uninfected HCC patients is due to lead-time bias. More intense surveillance of HIVinfected than uninfected patients would be expected to lead to earlier HCC diagnosis with better prognosis and survival which was not observed in this study.

An important limitation of this study is recruitment bias; because we recruited HCC cases only from oncology units of state-owned tertiary hospitals, we may have missed patients presenting with HCC at primary health care facilities and therefore unable to recruit all cases. In the setting of a strong health care system, such patients might be diagnosed earlier and survive longer. However, anecdotal evidence suggests that even if patients presented to the primary care facilities with early-stage HCC, those facilities are not equipped or staffed with appropriately trained individuals to provide early detection and effective treatment. It is more likely that our recruitment approach missed patients with HCC who did not survive long enough (after referral to confirm a tentative diagnosis) to be seen at the recruiting sites for this study. It is unlikely that HIV and HBV infection would be less prevalent among such patients than among those in this cohort.

Our findings suggest that HIV infection may cause early development of $\mathrm{HCC}$ in HBV-infected patients, particularly in females, and that many patients who present late with $\mathrm{HCC}$ have underlying undiagnosed and/or untreated HBV infection. Estimates suggest that only $5 \%$ of patients infected with viral hepatitis are aware of their infection status prior to HCC diagnosis [39]. Most of the HIV-infected patients in our study were aware of their HIV status. However, very few were aware of their HBV status.

\section{Conclusions}

Our results highlight the need to address the problem of hepatitis B within sub-Saharan Africa. The majority of childhood-acquired HBV infections become chronic, and $\mathrm{CHB}$ is the greatest risk factor for HCC in sub-Saharan Africa. HBV birth dose vaccination is the cornerstone to the HBV prevention strategy and should be available to all infants, particularly those born in high prevalence countries. The South African Ministry of Health takes the position that it is unnecessary to screen HIVinfected individuals for HBV because the current first line ART that includes tenofovir and lamivudine is active against both HIV and HBV. However, the hypothesis that ART is sufficient to prevent the evolution of HCC in HIV-infected patients needs further study. In order to identify those most at risk of HCC, there is a need to screen HIV-infected individuals for HBV, to treat those who test positive for HBV, and to vaccinate those who are not immune. In addition, better screening and management strategies for HCC should be developed for sub-Saharan African populations, where young people, especially those infected with HIV are at risk of this rapidly fatal malignancy.

\section{Abbreviations}

HIV: human immunodeficiency virus; HBV: hepatitis B virus;

HCC: hepatocellular carcinoma; HCV: hepatitis C virus; CHB: chronic hepatitis B; HBsAg: HBV surface antigen; ART: antiretroviral therapy; SSA: Sub-Saharan Africa; AFP: alpha fetoprotein; 95\% Cl: 95\% confidence interval

\section{Acknowledgements}

We wish to thank Professor Michael Kew for help with refining the research questions. Many thanks to the staff at the Tygerberg Hospital X-Block.

\section{Authors' contributions}

M.I.A, and J.S.J developed the research question; T.G.M, H. V, B. R, S. B, MB, J.O-J, P. R and M.I.A recruited patients and collected data. T.G.M, R.H.G, W. P, J.S.J, A.I.N, and M.I.A contributed to the data analysis. T.G.M, R.H.G, S. B, M. B, W.P, J.S.J, and M.I.A wrote the manuscript. All authors read and approved the final manuscript draft.

\section{Funding}

The research described in this report was supported by the Columbia University - South Africa Training Program for Research on AIDS-related Malignancies through the National Cancer Institute, NIH (Grant \# 1D43CA153715), the Poliomyelitis Research Foundation, the Harry Crossley Foundation and the South African National Health Laboratory Services 
Research Trust. The content is solely the responsibility of the authors and does not necessarily represent the official views of the funders. The funders did not have an influence on the design of the study and collection, analysis, and interpretation of data and in writing the manuscript.

\section{Availability of data and materials}

The data that support the findings of this study are available from Stellenbosch University upon reasonable request and with the permission of Stellenbosch University.

\section{Ethics approval and consent to participate}

All participants were recruited following written informed consent according to the Declaration of Helsinki 2008. Ethical approval for the study was obtained from the health research ethics committees at the Universities of Stellenbosch, Cape Town and Witwatersrand.

\section{Consent for publication}

Not applicable.

\section{Competing interests}

The authors declare that they have no competing interests.

\section{Author details}

${ }^{1}$ Division of Medical Virology, Stellenbosch University, Faculty of Medicine and Health Sciences, Cape Town, South Africa. ${ }^{2}$ Division of Medical Microbiology \& Immunology, Stellenbosch University, Faculty of Medicine and Health Sciences, Cape Town, South Africa. ${ }^{3}$ Tygerberg Business Unit, National Health Laboratory Service, Cape Town, South Africa. ${ }^{4}$ Division of Radiation Oncology, Stellenbosch University, Faculty of Medicine and Health Sciences, Cape Town, South Africa. ${ }^{5}$ Division of Radiation Oncology, University of Cape Town, Cape Town, South Africa. ${ }^{6}$ Department of Surgery, University of Cape Town, Cape Town, South Africa. ${ }^{7}$ Department of Surgery, University of Witwatersrand, Johannesburg, South Africa. ${ }^{8}$ Division of Medical Oncology, University of Witwatersrand, Johannesburg, South Africa. ${ }^{9}$ Department of Medicine, College of Physicians and Surgeons, Columbia University, New York, USA. ${ }^{10}$ Herbert Irving Comprehensive Cancer Center, College of Physicians and Surgeons, Columbia University, New York, USA.

${ }^{11}$ Mailman School of Public Health, Columbia University, New York, USA.

${ }^{12}$ Department of Microbiology, Oxford University Hospitals NHS Foundation Trust, Oxford, UK.

\section{Received: 31 May 2019 Accepted: 7 July 2020}

Published online: 13 July 2020

\section{References}

1. Ferlay J, Shin HR, Bray F, Forman D, Mathers C, Parkin DM. Estimates of worldwide burden of cancer in 2008: GLOBOCAN 2008. Int J Cancer. 2010; 127(12):2893-917.

2. Bosch FX, Ribes J, Diaz M, Cleries R. Primary liver cancer: worldwide incidence and trends. Gastroenterology. 2004;127(5 Suppl 1):S5-S16.

3. Han YF, Zhao J, Ma LY, Yin JH, Chang WJ, Zhang HW, Cao GW. Factors predicting occurrence and prognosis of hepatitis-B-virus-related hepatocellular carcinoma. World J Gastroenterol. 2011;17(38):4258-70.

4. Ferlay J, Soerjomataram I, Dikshit R, Eser S, Mathers C, Rebelo M, Parkin DM, Forman D, Bray F. Cancer incidence and mortality worldwide: sources, methods and major patterns in GLOBOCAN 2012. Int J Cancer. 2015;136(5): E359-86.

5. Kew MC, Geddes EW. Hepatocellular carcinoma in rural southern African blacks. Medicine (Baltimore). 1982;61(2):98-108.

6. Kiire CF. Hepatocellular carcinoma in Zimbabwe. Trop Gastroenterol. 1988; 9(3):127-31.

7. Kew MC. Epidemiology of hepatocellular carcinoma in sub-Saharan Africa. Ann Hepatol. 2013;12(2):173-82.

8. Ott JJ, Stevens GA, Groeger J, Wiersma ST. Global epidemiology of hepatitis $B$ virus infection: new estimates of age-specific HBsAg seroprevalence and endemicity. Vaccine. 2012;30(12):2212-9.

9. Andersson MI, Maponga TG, ljaz S, Barnes J, Theron GB, Meredith SA, Preiser W, Tedder RS. The epidemiology of hepatitis B virus infection in HIVinfected and HIV-uninfected pregnant women in the Western cape, South Africa. Vaccine. 2013;31(47):5579-84.
10. Tsebe KV, Burnett RJ, Hlungwani NP, Sibara MM, Venter PA, Mphahlele MJ. The first five years of universal hepatitis B vaccination in South Africa: evidence for elimination of HBsAg carriage in under 5-year-olds. Vaccine. 2001;19(28-29):3919-26.

11. UNAIDS. Fact Sheet 2015 in Fast-Track strategy to end the AIDS epidemic by 2030. https://www.unaids.org/sites/default/files/media_asset/20150901_ FactSheet_2015_en.pdf. Accessed 1 Nov 2015.

12. Deeks SG, Phillips AN. HIV infection, antiretroviral treatment, ageing, and non-AIDS related morbidity. BMJ. 2009;338:a3172.

13. Tanon A, Jaquet A, Ekouevi DK, Akakpo J, Adoubi I, Diomande I, Houngbe F, Zannou MD, Sasco AJ, Eholie SP, et al. The spectrum of cancers in West Africa: associations with human immunodeficiency virus. PLoS One. 2012; 7(10):e48108.

14. Smith CJ, Ryom L, Weber R, Morlat P, Pradier C, Reiss P, Kowalska JD, de Wit S, Law M, el Sadr W, et al. Trends in underlying causes of death in people with HIV from 1999 to 2011 (D:a:D): a multicohort collaboration. Lancet. 2014:384(9939):241-8.

15. Monforte A, Abrams D, Pradier C, Weber R, Reiss P, Bonnet F, Kirk O, Law M, De Wit S, Friis-Moller N, et al. HIV-induced immunodeficiency and mortality from AIDS-defining and non-AIDS-defining malignancies. AIDS. 2008;22(16): 2143-53.

16. Salmon-Ceron D, Rosenthal E, Lewden C, Bouteloup V, May T, Burty C, Bonnet F, Costagliola D, Jougla E, Semaille C, et al. Emerging role of hepatocellular carcinoma among liver-related causes of deaths in HIVinfected patients: the French national Mortalite 2005 study. J Hepatol. 2009; 50(4):736-45.

17. Weber R, Sabin CA, Friis-Moller N, Reiss P, El-Sadr WM, Kirk O, Dabis F, Law MG, Pradier C, De Wit S, et al. Liver-related deaths in persons infected with the human immunodeficiency virus: the D:a:D study. Arch Intern Med. 2006; 166(15):1632-41.

18. Brau N, Fox RK, Xiao P, Marks K, Naqvi Z, Taylor LE, Trikha A, Sherman M, Sulkowski MS, Dieterich DT, et al. Presentation and outcome of hepatocellular carcinoma in HIV-infected patients: a U.S.-Canadian multicenter study. J Hepatol. 2007;47(4):527-37.

19. Puoti M, Bruno R, Soriano V, Donato F, Gaeta GB, Quinzan GP, Precone D, Gelatti U, Asensi V, Vaccher E, et al. Hepatocellular carcinoma in HIV-infected patients: epidemiological features, clinical presentation and outcome. AIDS. 2004;18(17):2285-93.

20. Clifford GM, Rickenbach M, Polesel J, Dal Maso L, Steffen I, Ledergerber B, Rauch A, Probst-Hensch NM, Bouchardy C, Levi F, et al. Influence of HIVrelated immunodeficiency on the risk of hepatocellular carcinoma. AIDS. 2008;22(16):2135-41.

21. Mak D, Babb de Villiers C, Chasela C, Urban MI, Kramvis A. Analysis of risk factors associated with hepatocellular carcinoma in black south Africans: 2000-2012. PLoS One. 2018:13(5):e0196057.

22. Garson JA, Grant PR, Ayliffe U, Ferns RB, Tedder RS. Real-time PCR quantitation of hepatitis $B$ virus DNA using automated sample preparation and murine cytomegalovirus internal control. J Virol Methods. 2005;126(1-2):207-13.

23. ljaz S, Arnold C, Dervisevic S, Mechurova J, Tatman N, Tedder RS, Naoumov NV. Dynamics of lamivudine-resistant hepatitis B virus during adefovir monotherapy versus lamivudine plus adefovir combination therapy. J Med Virol. 2008;80(7):1160-70

24. Venook AP, Papandreou C, Furuse J, de Guevara LL. The incidence and epidemiology of hepatocellular carcinoma: a global and regional perspective. Oncologist. 2010;15(Suppl 4):5-13.

25. Carriaga MT, Henson DE. Liver, gallbladder, extrahepatic bile ducts, and pancreas. Cancer. 1995;75(1 Suppl):171-90.

26. Zuma K, Shisana O, Rehle TM, Simbayi LC, Jooste S, Zungu N, Labadarios D, Onoya D, Evans M, Moyo S, et al. New insights into HIV epidemic in South Africa: key findings from the national HIV prevalence, incidence and behaviour survey, 2012. Afr J AIDS Res. 2016;15(1):67-75.

27. Ramjee G, Daniels B. Women and HIV in sub-Saharan Africa. AIDS Res Ther. 2013;10(1):30

28. HIV and AIDS estimates (2015) [http://www.unaids.org/en/regionscountries/ countries/southafrica]. Accessed 2 Feb 2016

29. Kew MC, Yu MC, Kedda MA, Coppin A, Sarkin A, Hodkinson J. The relative roles of hepatitis $B$ and $C$ viruses in the etiology of hepatocellular carcinoma in southern African blacks. Gastroenterology. 1997;112(1):184-7.

30. Kew MC, Kramvis A, Yu MC, Arakawa K, Hodkinson J. Increased hepatocarcinogenic potential of hepatitis B virus genotype a in bantuspeaking sub-saharan Africans. J Med Virol. 2005;75(4):513-21. 
31. Yang HI, Lu SN, Liaw YF, You SL, Sun CA, Wang LY, Hsiao CK, Chen PJ, Chen DS, Chen CJ. Hepatitis B e antigen and the risk of hepatocellular carcinoma. N Engl J Med. 2002;347(3):168-74.

32. Kew MC. Hepatitis B virus infection: the burden of disease in South Africa. South Afr J Epidemiol Infect. 2008;23(1):4-8.

33. Mandishona E, MacPhail AP, Gordeuk VR, Kedda MA, Paterson AC, Rouault TA, Kew MC. Dietary iron overload as a risk factor for hepatocellular carcinoma in black Africans. Hepatology. 1998;27(6):1563-6.

34. Kew MC. Hepatocellular carcinoma with and without cirrhosis. A comparison in southern African blacks. Gastroenterology. 1989;97(1):136-9.

35. Paterson AC, Kew MC, Herman AA, Becker PJ, Hodkinson J, Isaacson C. Liver morphology in southern African blacks with hepatocellular carcinoma: a study within the urban environment. Hepatology. 1985;5(1):72-8.

36. Yoshida Y, Kanematsu T, Matsumata T, Sugimachi K, Kew MC, Paterson AC. A comparative study on hepatocellular carcinoma between south Africans and Japanese from the viewpoint of nuclear DNA content. Br J Cancer. 1994;69(2):362-6.

37. Singal AG, Yopp AC, Gupta S, Skinner CS, Halm EA, Okolo E, Nehra M, Lee WM, Marrero JA, Tiro JA. Failure rates in the hepatocellular carcinoma surveillance process. Cancer Prev Res (Phila). 2012;5(9):1124-30.

38. Walker M, El-Serag HB, Sada Y, Mittal S, Ying J, Duan Z, Richardson P, Davila $J A$, Kanwal F. Cirrhosis is under-recognised in patients subsequently diagnosed with hepatocellular cancer. Aliment Pharmacol Ther. 2016;43(5): $621-30$

39. WHO: Global health sector strategy on viral hepatitis, 2016-2021. In.; 2016. http://apps.who.int/iris/bitstream/10665/246177/1/WHO-HIV-2016.06-eng. pdf?ua=1. Accessed 16 Sept 2016.

\section{Publisher's Note}

Springer Nature remains neutral with regard to jurisdictional claims in published maps and institutional affiliations.

Ready to submit your research? Choose BMC and benefit from:

- fast, convenient online submission

- thorough peer review by experienced researchers in your field

- rapid publication on acceptance

- support for research data, including large and complex data types

- gold Open Access which fosters wider collaboration and increased citations

- maximum visibility for your research: over $100 \mathrm{M}$ website views per year

At BMC, research is always in progress.

Learn more biomedcentral.com/submissions 